\title{
Impact of COVID -19 on Pilot Proficiency - A Risk Analysis
}

\author{
Rajee Olaganathan * and Roli Angelo H Amihan \\ Embry-Riddle Aeronautical University - Worldwide, USA \\ Global Journal of Engineering and Technology Advances, 2021, 06(03), 001-013
}

Publication history: Received on 17 January 2021; revised on 19 February 2021; accepted on 21 February 2021

Article DOI: https://doi.org/10.30574/gjeta.2021.6.3.0023

\begin{abstract}
Pilot proficiency is essential in the aviation industry to maintain a safety record for successfully operating airlines. The current COVID-19 scenario has made it practically difficult for pilots to achieve the federal requirements stated in Title 14 CFR 121.439 (a) and 14 CFR 61.57 (a) (1). It has placed a burden on pilots to maintain their currency and proficiency related to cost and lack of aircraft access due to furloughs and lay-offs. The purpose of the first part of this study was to assess the impact of COVID-19 on global air traffic based on the data collected from the International Civil Aviation Organization (ICAO) and the U.S. Bureau of Transportation Statistics (BTS). The second part of this research study aims to assess the pilot's proficiency before and after COVID-19 was officially declared as pandemic to identify any threats to aviation safety based on the incident reports submitted in the Aviation Safety Reporting System. The findings show that the highest reduction in flight operations was observed during May 2020 with $-70.67 \%$ compared with May 2019 at the global level. Middle East region witnessed a $-57.35 \%$ reduction in flight operations. Based on the number of flights operated in the year 2020, the Asia-Pacific region was the most affected region with 4,913,303 fewer flights than in the year 2019. For the U.S. domestic air traffic, a severe impact occurred in May 2020 with a $-70.88 \%$ reduction and 532,834 fewer flights than in May 2019 which was similar to the global air traffic trend. The number of incident reports filed by pilots regarding proficiency-related to COVID-19 issues in the ASRS data analysis increased by $1000 \%$ during this pandemic period. The results and recommendations of this research study will provide valuable information to the aviation industry that can aid in developing mitigation measures to decrease future aviation accidents related to pilot proficiency.
\end{abstract}

Keywords: COVID-19; Flight proficiency; Aviation safety; Flight skills; Pilot re-currency

\section{Introduction}

Air travel is a crucial part of transportation around the world. Air transportation is also vulnerable to external threats like recession, natural disaster, oil crises, and disease outbreaks. These threats severely affect global air travel by increasing flight cancellations, causing the grounding of aircraft, travel bans, and closure of international borders. These threats have affected both the aeronautical and non-aeronautical revenues [1]. Mehta [2] reported that the aviation industry has contributed to 3.6 percent of the world's GDP by creating a total of 65.6 million jobs both directly and indirectly.

The most significant disease outbreak that affected aviation industry in terms of air traffic before Covid-19 was SARS (Severe Acute Respiratory Syndrome) that occurred in 2003. After nearly seventeen years, COVID-19 has emerged as a public health emergency around the world. By the end of March 2020, approximately 98 percent of the global air transport passenger revenues faced severe restrictions like quarantine for arriving passengers, partial travel bans, and complete border closures in a few countries. COVID - 19 has affected the day-to-day life of people worldwide, and most of the countries have prioritized public health over economic growth and have ceased their flying operations.

\footnotetext{
${ }^{*}$ Corresponding author: Rajee Olaganathan

Embry-Riddle Aeronautical University - Worldwide.
}

Copyright (C) 2021 Author(s) retain the copyright of this article. This article is published under the terms of the Creative Commons Attribution Liscense 4.0. 
The International Civil Aviation Organization [3] estimated that there would be a decrease of 503 to 607 million passengers, a reduction of $47 \%$ to $58 \%$ of seats offered by airlines, and a loss of airlines revenue would be 112 to 135 billion USD [3]. ICAO also estimated that the Revenue-Passenger- Kilometres (RPKs) would decrease by 48 percent, and there will be a slower growth during the second half of 2020 [4]. The operational impact of COVID-19 on Air Transport shows a dramatic drop in domestic and international flights in the consecutive months after it was declared a pandemic. The vast difference exists from a month-to-month difference comparison, which started in March 2020 with a difference of $(-932,861)$ flights and peaked in May 2020 with $(-2,740,759)$ flights of the same period from the prior year. The report also shows a breakdown in percentage difference for each region in which the Middle East region showed the largest decrease in flights with (-59.64\%) [5]. The reduction of flights due to lockdown translated to several pilots not flying, and many of whom were furloughed or laid-off by their companies. It further resulted in the lack of access to regular currency tool simulators that are expensive but essential in maintaining piloting skills to a high degree of safety.

As a highly technical field, piloting an aircraft requires proficient operators, as it is already an inherently high-risk field. According to the Federal Aviation Administration [6], in the general aviation industry (GA), there are five contributing factors as to why aircraft that figured in a loss of control accidents occur. These factors are disorientation, distraction, startled response, lack of aircraft handling skills, and inadequate risk management. Among these, the "lack of aircraft handling skills" is related to pilot proficiency, which requires performance and practice. Data gathered by the International Civil Aviation Organization (ICAO) from 2008 to 2019 suggests that Loss of Control- In-flight (LOC-I) for scheduled commercial flight category has been low and has a downward trend [7] (Fig. 1).

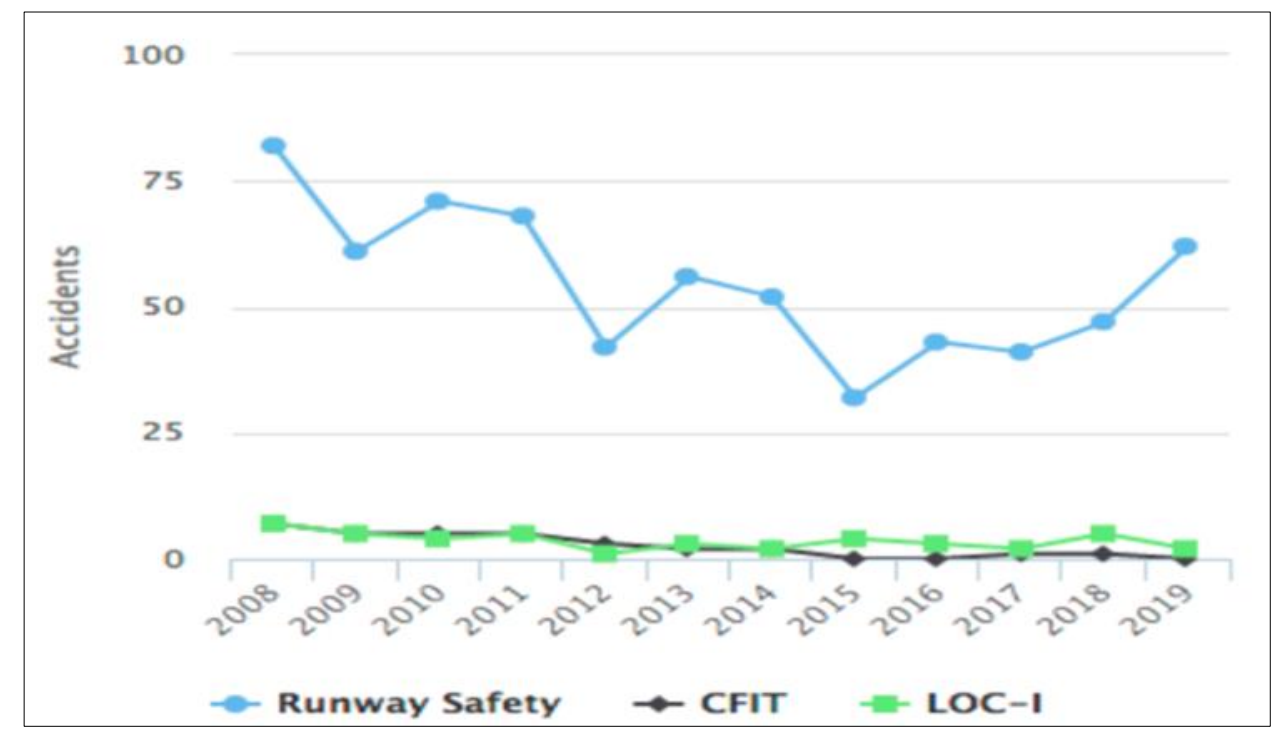

Figure 1 Scheduled commercial Flight Accident by Risk Category

Note: Adapted from "International Civil Aviation Organization - Accident Statistics Data" [7]

In terms of fatalities, compared with controlled flight into terrain (CFIT) and runway safety, the highest mortality was related to LOC-I (Fig. 2). LOC-I incidents/accidents occur due to the pilot's lack of piloting skills and is mainly associated with a reduced pilot's proficiency. As the proficiency and LOC-I are related, it requires a closer examination if the industry intends to maintain the low level and downward trend of LOC-I accidents and reduce the fatalities related to this risk category [7]. 


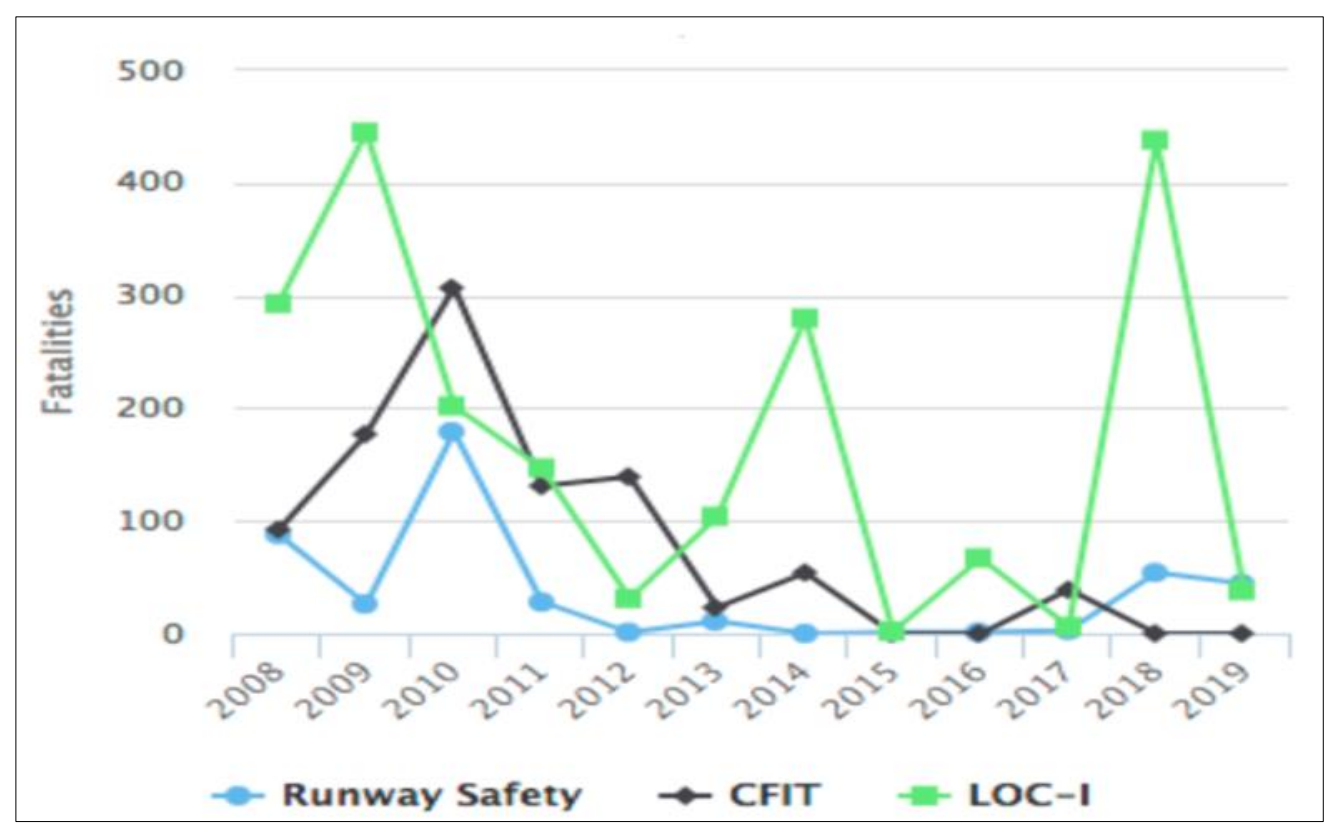

Figure 2 Scheduled Commercial Flight Fatalities by Risk Category

Note: Adapted from "International Civil Aviation Organization - Accident Statistics Data" [7]

These data clearly show that any deficiency in pilot proficiency poses a threat to aviation safety. Therefore, this research focuses on acquiring an overview of the COVID-19 scenario, pilot skills degradation, and the significance of flying expertise. It will also identify whether COVID-19 has made any significant impact on pilot proficiency by identifying the associated hazards and thorough risk analysis. Further, this research study will also provide valuable information to develop mitigation measures to reduce future aviation accidents related to pilot proficiency.

\subsection{Corona Virus}

Coronavirus had a tremendous impact on people's lives, and it even dictates what people can and cannot do concerning their day to day activities. The aviation industry is one of the hardest-hit businesses in the world, as the pandemic created uncertainty. Virtually all economies have come to a complete halt as businesses were closed down, travel is limited to essential, and to the closing down of airspace to stop the virus spread further. Only after an effective and safe vaccine is developed the world will see the pre-COVID activities resume. It might even take a while for most of the industries to rise again. A thorough knowledge about the virus, how it progresses, and how it affects its victims will provide a perspective that might help to develop mitigating measures to combat it.

SARS-COV-2, popularly known as COVID-19, belongs to a group of coronaviruses that mainly affect its host's respiratory system. Although many of these viruses are common to animals, an animal to human transmission can occur [8]. In 2002 and 2012, China and Saudi Arabia have documented outbreaks relating to this family of coronaviruses, namely SARS and MERS. The transmission mode from animal to human is direct contact with the infected animal carrier, most commonly bats. The early stages of transmission indicate that an animal to the human transmission may have occurred and eventually led to human-to-human transmission. First reports of the COVID-19 were traced back to a seafood market in Wuhan province in China. It resulted in its shutdown early in the first quarter of the year 2020.

According to Cohut (2020), some of the infected people have not been to Wuhan, and further investigation revealed that Wuhan might not be the only source of the virus [8]. Research also found that some infected people showed severe symptoms, while some develop moderate to no symptoms known as asymptomatic cases. The virus has an incubation period of fourteen days, and infection can be confirmed only through testing. The spread of COVID-19 was unprecedented. Until an effective and safe vaccine has been developed, the Center for Disease Control and Prevention (CDC) advocates limiting people's gathering, using approved masks, and frequent washing of hands to slow its spread. Social distancing measures have also been in place, and various governments have also implemented a strict lockdown that has affected their economy. 
A pandemic is a health condition that spreads globally. However, before it reaches the pandemic stage, it passes through other stages like endemic, outbreak, epidemic, and finally attains the pandemic stage. According to Grennan [9] the medical terms endemic, outbreak, epidemic, and pandemic are designated to categorize infections per how many cases there are and the expanse for which it has spread geographically. Among the four stages, the endemic stage is stable and predictable as the number of infected people is close to the predicted number. The infected people are usually located within a country or town or in larger areas such as continents or countries. Some diseases classified under the endemic stage are Dengue in South East Asia or Malaria in Africa. The epidemic stage refers to a sudden increase in the number of disease cases above the expected number. Zirka virus and Ebola is an excellent example of this. The outbreak stage is similar to the epidemic stage, but it is limited to a geographical area. Some examples of diseases under this category are the Cholera outbreak after the Haiti earthquake and the Ebola in Africa's different parts. In the pandemic stage, the infection spreads across several countries and affects a large number of people.

Before the COVID-19 pandemic, the Spanish flu is one of the most serious due to the magnitude of infection and the number of lives it has claimed. Essentially, the classification of diseases based on the number of infected and the magnitude of how far it spreads, and its manner of spread provide strategies to contain or mitigate it. The highly globalized world with people's movement from one place to another via air travel has provided an ideal platform for the fast spread of the infection. These diseases can be transported from one part of the globe to another in a matter of hours. When compared to an era before air travel, it is safe to assume that restricting air travel during a global pandemic will provide a means for every government to slow it down and mitigate how it spread within a local setting.

\subsection{COVID-19 Timeline}

The coronavirus (COVID-19) pandemic has affected almost all business operations globally. Most of the countries around the world have prohibited cross-country transportation and have closed their borders. The first COVID-19 case was reported in China in 2019 on 31st December. Upon confirmation of an outbreak in Wuhan, the WHO instructed its local office to activate the Incident Management Support Team (IMST) to manage and support medical personnel in the region. Four days after the recorded case, the WHO's social media posted pneumonia-like cases in the Wuhan region with zero deaths at the time. On January 5th, 2020, the WHO announced the emergence of a new virus. The announcement also included information related to the risk assessment, advice, and the status of the infected people in Wuhan and China's response. WHO published a standard protocol for member nations regarding the detection, test, and management of potential cases based on the limited available information about the virus on January 10 th, 2020. Continuous coordination with the Chinese government led to the publication of the genetic sequence essential for developing a vaccine. Outside China, the first infected case was reported by Thailand on January 13th [10].

The series of events that unfolded in Wuhan prompted the WHO to deploy their Pacific Regional Team for a brief visit in Wuhan to see the actual events taking place and conduct a further investigation related to the magnitude of disease transmission. The report submitted by this team prompted WHO to declare the situation as a "public emergency" on January 23rd, 2020. The WHO also sent aid to Beijing to assess governmental response and offer technical expertise to combat the spread. On February 3rd, 2020, the WHO issued a Strategic Preparedness Plan given the preparation necessary for developing countries whose health care system is not as robust as those found in more developed nations. To further strengthen the strategy in dealing with the growing outbreak, the WHO called for a forum relating to research and innovation to promote a collaborative approach in dealing with the situation. Despite the effort, a major outbreak occurred in Italy (February 21s, 2020) [10]. Based on the series of events and the uncontrolled, alarming, and rapid spread of the virus and the severity of its victims, WHO declared COVID-19 as a global pandemic outbreak on March 11 th, 2020 [11].

\subsection{Possible Climax of COVID - 19}

Similar to any past pandemic that has ravaged the earth, human resiliency has always prevailed. There are two possible scenarios in which the COVID-19 pandemic might end. Based on the medical history evaluation, two theories emerged regarding how past pandemics and outbreaks have ended. It is either a social ending or a medical ending. The social end of a pandemic does not mean that the disease has vanished. Instead, society has grown tired of being in a state of panic and thus learned to co-exist with it while following secure protocols to minimize the possibility of contracting the disease [12]. In short, people return to their activities, hoping not to catch the virus while taking certain precautions and going on with their daily lives. An example of a social ending is the Spanish flu in which during that era that coincided with World War I and other wars, people have gone so tired that they just ignored or risked living their daily lives despite claiming thousands of lives. Eventually, the disease mutated to a lesser form of flu, and people have learned to co-exist with it while taking all possible precautions. The medical ending occurs when the incidence and death rates decrease. Examples of a medical ending stage are the Plague of Justinian, in which it claimed almost half the world's 
population. As a result, the disease ran out of people to infect, and medical experts concluded that survivors might have developed some immunity.

Both social and medical ending is not a "complete ending" for COVID-19 as the disease will always be there. People will learn or evolve to deal with it either through naturally developing immunity, taking a vaccine, practicing protocols to limit its spread within geographical areas, and the virus mutates to a less deadly form. Thus, it is safe to assume that people's activities, especially relating to the aviation industry in one way or another, will have to pick up some time in the near or far future. Whenever that be pilots' must be proficient before finding themselves on the flight deck for safety reasons.

\subsection{Pilot Skill Degradation}

As a highly technical and inherently risky field, the aviation industry heavily depends on pilot proficiency to reduce operational risks to the lowest levels. However, a pilot's competency depends highly on how frequently they perform the critical skills associated with safe flying. Ammons et al. [13] assessed the pilot's skill retention ability related to a long period of disuse and, in general, observed a decline or downward trend. The experiment that was performed by Ammons et al. [13] included training the participants eight hours a day to achieve proficiency for a specific flight task. The training was stopped with an interval ranging from 24 hours to two years, and then the skills were re-assessed. This experiment's result revealed that the longer the skill was not performed or practiced, the related proficiency declined [13]. Fleisman \& Parker [14] also reported a similar observation in which they noted a decline in pilot proficiency as the skill is not practiced or performed. When the practice or training resumed, the proficiency returned up to $75 \%$. The same issue prevailed among private pilots who failed to regularly perform critical flight maneuvers and emergency procedures after their check ride on as little as eight months [15].

A noteworthy accident in which pilot proficiency was one of the main contributing factors to the incident is the Colgan Air Flight 3407 crash. In 2009, Colgan Bombardier DHC 8400 was on an instrument approach to Buffalo Niagara International Airport, New York. During that approach, it crashed into a residence in Clarence Center, New York, about five nautical miles northeast of the airport. All the passengers and crew members on board died, and it also killed one person on the ground. The impact forces caused a post-crash fire that destroyed the aircraft. The NTSB investigation team revealed that the captain inappropriately responded to the activation of the stick shaker, and it led to an aerodynamic stall from which the airplane did not recover [16]. The captain's incorrect input resulted in the aircraft stalling even more. Eventually, it led to a loss of control in fight or LOC-I which was related to the pilot's proficiency. The investigators failed to figure out what led the captain to provide an incorrect input on the flight control. As per federal regulations, he has to demonstrate a stall recovery maneuver every six months, and the first officer has to demonstrate this skill once a year. This accident indicated that currency training is essential to maintain the proficiency level of the cabin crew.

Another notable incident in which a pilot's proficiency had been in question involved United Airlines Flight 863 near collision to the San Bruno Mountains. Although the incident did not result in any loss of lives and property, both the pilots filed a voluntary incident report program within the company for other pilots to avoid the same mistake. According to Johnson [17] the Sydney bound aircraft lost power while taking off from San Francisco airport, causing it to fly too low and barely clearing the San Bruno Mountains and missing it by only 100 feet. The flight had two aircrew sets for relieving and fatigue management purposes, as it was a 14 hour and 25 -minute journey from San Francisco to Sydney, Australia. As the aircraft started to lift-off, it experienced an engine failure on the right. Although the co-pilot initially performed the correct procedure by shutting down the affected engine, the aircraft started to veer off to the right due to asymmetric thrust being higher from the left side. The correct procedure for that scenario would have been to step on the left rudder to compensate for asymmetric thrust. However, the co-pilot's succeeding action resulted in the stick shaker to be activated a signal for approaching stall conditions as he turns the yoke to the right. The other flight crew shouted to push down the yoke with the impending loss of lift on the right-wing. As the situation progressed, the aircraft was veering its original course heading for the San Bruno Mountains. With the rising terrain, the ground proximity warning activated, warning the pilots of the impending danger. The aircraft eventually cleared the mountain with only 100 feet to spare, way below the minimum altitude of 500 feet as prescribed by regulation. Soon after, the captain took control and proceeded back to the airport for an emergency landing [17].

The investigation indicated the lack of pilots' proficiency is the reason for the incident. For example, a crew of regional flights may perform several take-offs and landings per day, thus providing an opportunity for both captain and first officer to take turns in practicing specific procedures. On the other hand, long-haul flight limits aircrew opportunities to take turns in practicing their take-off and landings as a majority of these flights may only consist of one take-off and landing. This system was in place to mitigating measure to fatigue aircrew that has performed the take-off from the 
point of departure and is replaced by the standby aircrew for the landing phase. Regarding the proficiency of the first officer of United Flight 863, the engine failure incident demonstrated that his recovery procedures were not his strong points, and he lacked proficiency despite flying regularly. These types of accidents and incidents that have occurred in the aviation industry around the world indicate that aviation safety might be affected in the current pandemic scenario due to lack of pilot proficiency related to furloughs, lay-offs, and lack of access to proficiency tools.

\subsection{FAA Requirements for Flying Skills}

The current scenario with the COVID-19 pandemic left several pilots with little to no ability to fly or maintain flight proficiency due to the decline in air travel since the start of the pandemic. Title 14 CFR $\S 61.57$ provides guidelines on what the pilot must accomplish to remain legal to fly or commonly known as a currency requirement to act as a Pilot in command. While Title 14 C.F.R. $\$ 121.439$ issues guidelines to Part 121 Operators to follow the regulations related to the currency requirements for their pilots.

However, meeting the currency requirements does not necessarily translate to a proficient pilot. One may be legal to fly but not necessarily proficient enough to be considered as a safe pilot. Puentes [18] explained that certified pilots might suffer from profound, rapid, and pervasive flight skill loss due to non-practice. This, explains the relationship between performing flight-related tasks and the pilot's ability or proficiency in performing them to a high standard. Further, piloting an aircraft is a combination of exercising both the motor skill and cognitive processing, which is highly dependent on the frequency it is being used or performed [18]. This is supported by another research study that explained the different types of skills involved to make sure that an aircraft maintains its flight path while ensuring pilot situational awareness involves the use of both the cognitive process and proficiency [15]. Similarly, essential skills necessary for instrument flight rules (IFR) wherein all Part 121 operators are mostly engaged are highly affected if not performed for long periods. This is because IFR flights require a high cognitive input from the pilots due to flying using the aircraft's instrument only and with little to no visual cues [19]. Other existing literature also affirms that if the cognitive skills learned from early flight training were not performed for long periods it tends to decline without appropriate practice [20]. This provides a foundation for why a commercial pilot check ride requires a candidate to demonstrate essential skills associated with areas of operation as flying is more than just taking off, straight \& level flight, and landing. There are essential skills wherein each pilot must demonstrate for him or her to be considered proficient. However, it is also a fact that these skills are not routinely practiced or performed during normal operation. The current pandemic makes it worse by limiting the pilot's access to tools that would keep them proficient until they are called inside the flight deck again.

Some of these skills are outlined in the Airmen Certification Standards for Commercial Pilot Airplane FAA-S-ACS-7A. These skills are the demonstration of normal takeoff and climbing, normal approach and landing, soft field takeoff and climb, soft field approach and landing, short-field takeoff and maximum performance climb, short-field approach and landing, power-off 180 accuracy approach and landing, steep turns, steep spirals, chandelles, lazy eights, eights on pylons, slow flights, power on and power off stalls, accelerated stalls, and spins to name a few. Similarly, pilots who fly aircraft that require type ratings common to Part 121 or scheduled flight operations must meet skill standards or at least be able to demonstrate them. The lists of skills that must be surpassed as proof of proficiency are provided in the Airmen Certification Standards for Airline Transport Pilot and Type Rating for Airplane FAA-A-ACS 11. Some of the skills that must be met by the pilots under this certificate are normal takeoff and climb, normal approach and landing, steep turns, recovery from unusual flight attitudes, partial flap configuration stall prevention, clean configuration stall prevention, landing configuration stall prevention, instrument procedures, and emergency procedures to name a few. One thing that is common for both Airmen Certification Standards (ACS) is that most maneuvers or tasks are not commonly performed under normal operation. Thus, there is gradual skill degradation under the normal scenario as time passes by without practicing these maneuvers. Additionally, the current pandemic situation aggravates the issue due to the limited access for pilots to practice and stay proficient.

Puentes [18] explains that in most flight phases, the brain's cognitive function is involved, which is similar to a muscle. It requires practice to ensure that this skill aligns with the information it receives. This information that requires cognitive processing includes the sensory cues that the body receives and flight information displayed on the aircraft instruments. The information received and perceived results in an appropriate output from the aircrew in terms of manipulation of flight controls. Baron [21] also supported the concept of cognitive processing through his explanation and comparison to a 'closed-loop system'. Accordingly, the physical sensing of the pilot and feeding of flight data triggers brain processing. It results from in-flight control adjustment as appropriate to achieving the flight's preferred airspeed, direction, and altitude. Furthermore, the 'closed-loop system' described is a fundamental skill for safely maintaining the aircraft's desired route. This puts a heavy demand on cognitive processing to process and translate the information into a meaningful control input [21]. 


\section{Research Method}

The first part of this research study assesses the impact of COVID-19 on global air traffic. The data for this study were collected from January 2019 to December 2020 from the ICAO database [5] and Bureau of Transportation Statistics [22]. The second part of this study aims to find whether pilots' proficiency in flying an aircraft was affected by COVID-19's impact on air travel. The data was collected from July 2019 to February 2020 (before pandemic), and eight months from March 2020 to October 2020 (after declaration as a pandemic in the U.S.) from NASA's Aviation Safety Report System (ASRS).

\subsection{Data Collection from ASRS Database}

The data were filtered to include incidents that occurred due to lack of proficiency despite meeting currency requirements in 14 CFR $\S 61.57$ and 14 C.F.R. $§ 121.439$. The other variables used to narrow down the data are the flight phase, reporter function, event type, and text, including currency, proficiency, Covid, and/or pandemic. The flight phase filter was set to further limit the flight phases relevant to the study like take-off, initial climb, cruise, descent, initial approach, and final approach. The reporter function filter essentially narrowed down the incident reports filed by aircrew (captain, check pilot, first officer, flight engineer, and second officer). This is based on the assumption that the aircrew has first-hand knowledge of the incident. Similarly, the event type filter was also selected to indicate what type of incident occurred. For this research study, the selected events included Controlled Flight into Terrain (CFIT)/ Controlled Flight to Terrain (CFTT), Loss of Control In-flight (LOC-I), and Un-stabilized approach, as these are the common incident associated with pilot's reduced or lack of proficiency. After collecting the data, each report was evaluated carefully to filter further incidents that do not meet the criteria set forth for this research. A mixed methodology (quantitative and qualitative) is used in this study [23].

\subsection{System Safety}

System safety is "important to the development of any system mainly to reduce the risks, protect lives and resources by preventing mishaps" [24, p.9]. Based on this system safety aim, the hazards related to pilot proficiency were identified. A Preliminary Hazard Analysis was also conducted using the methodology obtained from MILSTD-882E for System Safety [25]. The identified hazards were organized based on the checklist provided in the book Risk Assessment: Theory, Methods, and Applications by Rausand [26] and the format of the table is adapted from the textbook Hazard Analysis Techniques for System Safety by Erickson [27]. Hazard Risk Assessment Matrix was adapted from MILSTD-882E for System Safety [25].

\subsection{Research Question and Selection of Statistical Tests}

The research question that guides this study are "Did COVID-19 impacted the global air traffic?" and "Does the ASRS reports indicate a difference in the pilot's proficiency or skill before COVID-19 vs. after declaring it as a pandemic?" The research question of whether COVID-19 impacted pilot proficiency was addressed by testing the null hypothesis. The selected data didn't meet the assumptions of parametric tests. Therefore, a non -parametric tests (Chi-square test Goodness of Fit) was carried out using the online software package Stat Crunch. For all the statistical tests an alpha level of .05 significance is used.

\section{Results and discussion}

\subsection{Impact of COVID-19 on Global and Regional Air Traffic}

The analysis of the data showed a drastic reduction in air traffic across the world. The trends in the monthly operations of global air traffic and the difference in the total number of flights between 2019 and 2020 were shown in Fig.3 on a monthly basis. The highest decrease was observed during May 2020 with 2,756,499 fewer flights (-70.67 \%) compared with May 2019, it was followed by April 2020 (- 2,576,305 flights with - 69.43 \%) and June 2020 (- 2,109,393 flights with - $53.40 \%$ ). 


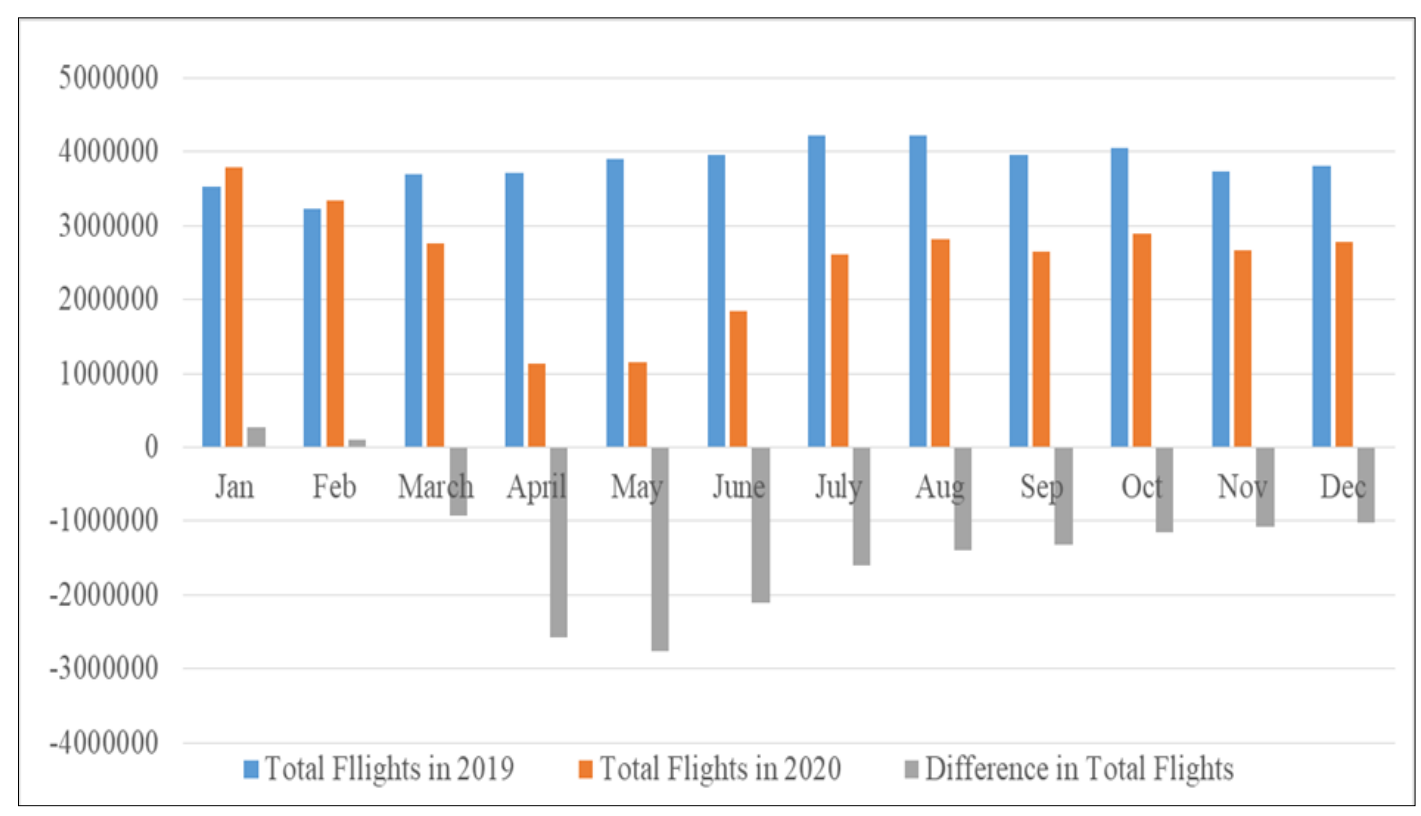

Figure 3 Impact of COVID-19 on the Global Flight Operations, January 2019 to December 2020

Fig.4. illustrates the impact of COVID-19 on air traffic based on the region of origin. The air traffic was heavily affected in the Middle-East region with a $-57.35 \%$ reduction. It was followed by Africa ( $-53.56 \%)$, Europe (-52.61 \%), and LatinAmerica and the Caribbean (-48.4\%). In terms of the number of flight operations, the Asia-Pacific region was the most affected with 4,913, 303 fewer flights than in 2019 and was followed by Europe $(-4,766,279)$ and North America ($3,211,278)$.

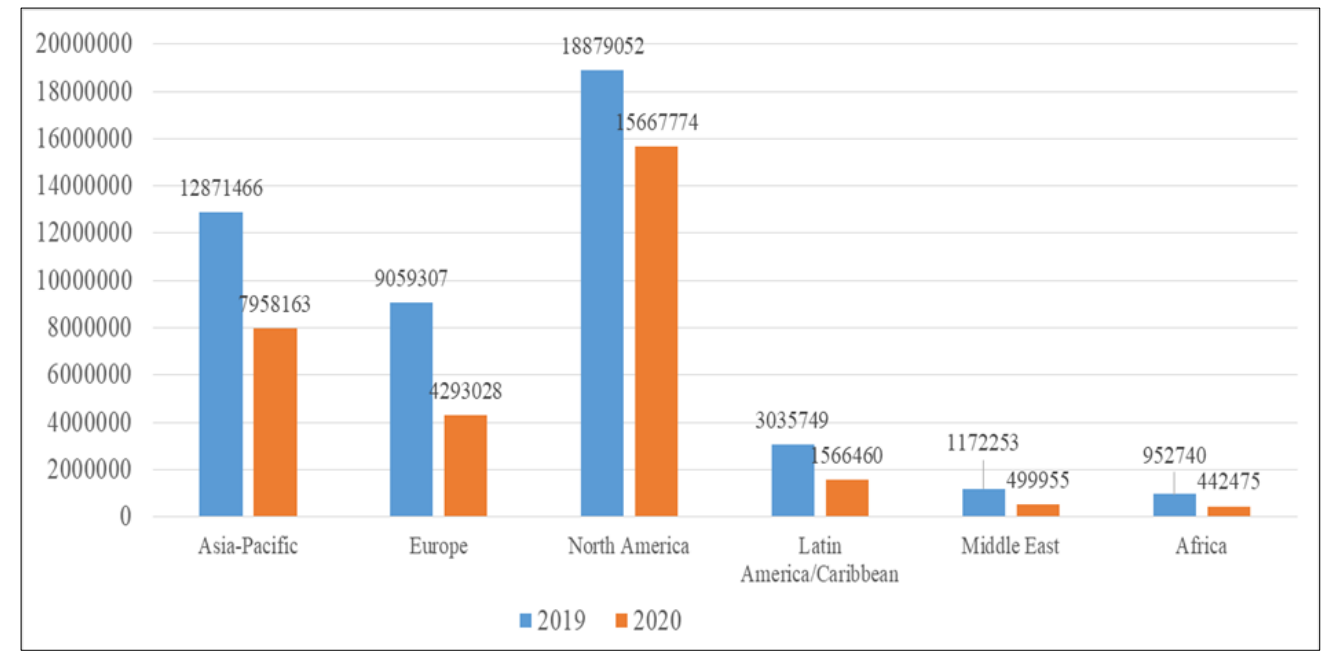

Figure 4 Impact of COVID-19 on the Flights Operations at Regional Level, January 2019 to December 2020

\subsection{Impact of COVID19 on U.S. Domestic Air Traffic}

As per the ICAO, the operational impact of COVID-19 on air transport in the United States was around $-14.47 \%$. The total flights operation in 2019 was 17,307,931 and in the year 2020 it decreased to 14,802,733 [5]. The analysis of the data obtained from the Bureau of Transportation on the domestic U.S. air travel revealed the effect of COVID-19 on air travel. Fig.5. shows the monthly decrease in the number of fights compared to year 2019 and 2020. The trend line of reduction in flight numbers in the U.S. was similar to the global air traffic. The major impact was observed in May 2020 with 532,834 fewer flights, which was a - 70.88 \% reduction compared to May 2019. This was followed by April 2020 ($69.39 \%)$ and June 2020 (-62.91\%) respectively. This observation of air traffic based on the region of origin revealed a similar decreasing trend which confirms the significant impact of COVID-19 on the aviation industry. The lesser 
number of flight operations will affect the pilots around the world in terms of proficiency and their currency. The following section discusses the impact of fewer flights on pilot efficiency.

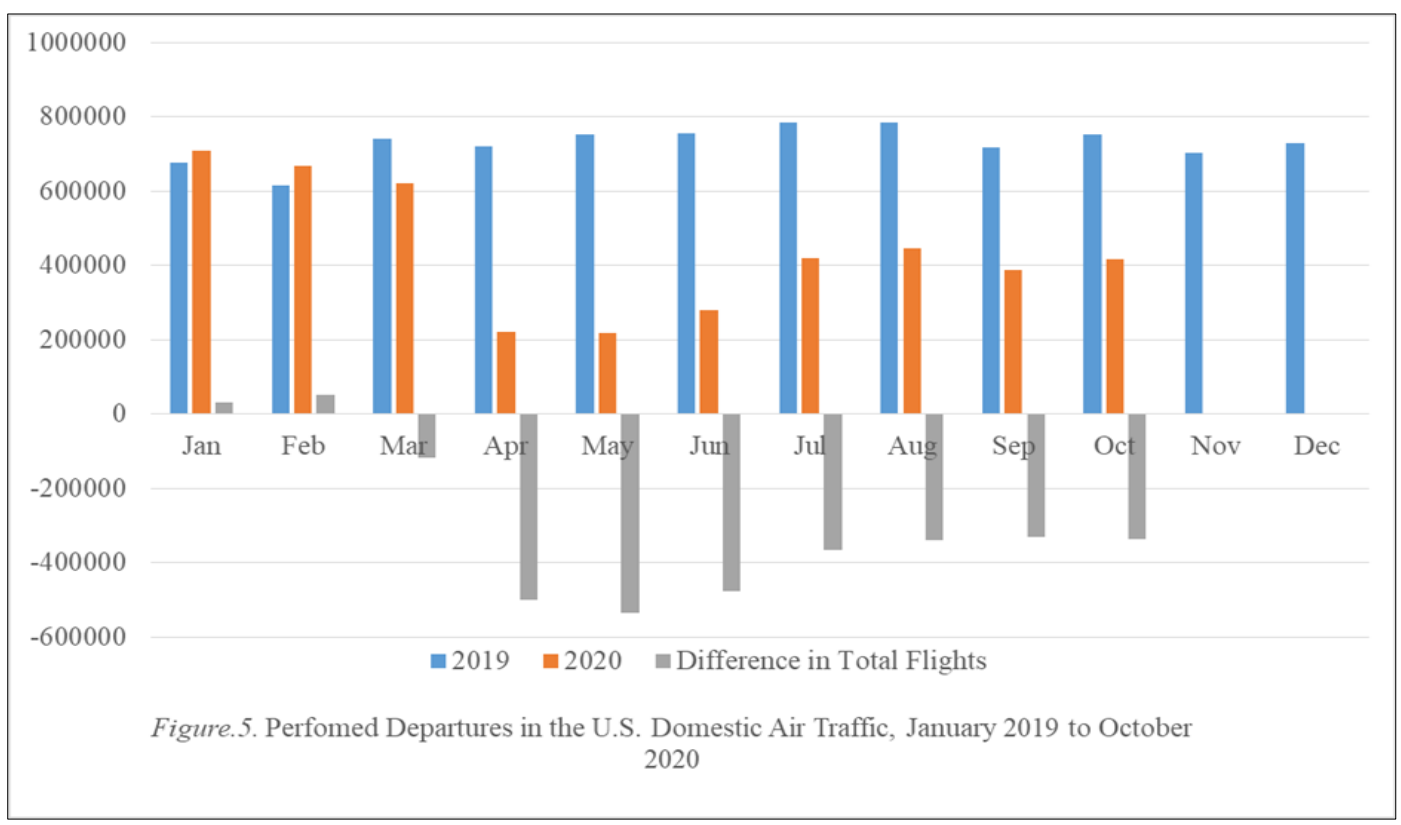

Figure 5 Performed Departures in the U. S. Domestic Air Traffic January 2019 to October 2020.

\subsection{Overview of the Incidents related to Pre-COVID and Post-COVID-19}

The data for the Pre-COVID period from July 2019 to Feb 2020 identified a total of 4,326 incident reports (Table 1). Out of that, there were 313 incidents related to CFIT, CFTT, LOC-I, and unstable approach. Among these reports, only one incident report indicated that the incident might be associated with a lack of proficiency and/or currency. While the ASRS data for the Post-COVID period from Mar 2020 to Oct 2020 provided a total of 2,412 incident reports (Table 1). Out of that, 175 incidents were related to CFIT, CFTT, LOC-I, and unstable approach. Among these, ten reports indicated that the incident might be due to the lack of proficiency and/or currency.

Table 1 Total number of ASRS reports that occurred during Pre-COVID and Post-Declaration of COVID.

\begin{tabular}{|l|l|l|l|}
\hline & Total Reports & $\begin{array}{l}\text { Inflight Incidents or Type of } \\
\text { Incidents (CFIT, CFTT, LOC-I, } \\
\text { \& Unstable Approach) }\end{array}$ & $\begin{array}{l}\text { Incident Attributed to } \\
\text { Proficiency or } \\
\text { Currency }\end{array}$ \\
\hline $\begin{array}{l}\text { Pre-COVID (July 2019 } \\
\text { to February 2020) }\end{array}$ & 4326 & 281 & 1 \\
\hline $\begin{array}{l}\text { Post-Declaration } \\
\text { March 2020 to October } \\
\text { 2020) }\end{array}$ & 2412 & 175 & 10 \\
\hline Total & 6738 & 456 & 11 \\
\hline
\end{tabular}

The Chi-Square test for goodness of fit $(\mathrm{p}<0.05)$ showed that the COVID-19 pandemic has significantly affected the pilot's proficiency which is a potential hazard for aviation safety. The ASRS database exhibited a significant increase in incident reports after COVID-19 was declared as a pandemic. The increase is $1000 \%$ just within a short time (one report prior to the pandemic was equal to ten reports after the declaration of a pandemic). Although more incident reports qualified based on the set parameters, the reports were read thoroughly to screen for the most accurate result. An interesting trend observed while screening the incident reports from ASRS is that several incident reports attributed the incident to decreased pilot proficiency due to reduced flying that occurred due to the COVID-19. The incident reports in the ASRS database that indicated this issue are ACN 1761579, ACN 1754995, ACN 1761850, ACN 1750618, ACN 1747388, ACN 1746738 ACN 1745186, ACN 1743435, ACN 1742866, and ACN 1739613. 


\subsection{Hazard Analysis}

During the past decade, the safety management system (SMS) is used as a tool to mitigate aviation-related hazards [28]. In 2006, the International Civil Aviation Authority (ICAO) mandated its member states to establish SMSs and the FAA to begin issuing advisory circulars for the SMS implementation in the U.S. In aviation SMS, hazard identification is the first essential step for its success and is followed by risk assessment and control [28].

COVID-19 pandemic has significantly affected the global aviation industry especially, the proficiency of pilots. There were fewer flight operations during this pandemic, and pilots lack access to tools required to maintain their flying skills due to furloughs and layoffs caused by the pandemic. It is considered a potential hazard for aviation safety. To proactively mitigate the hazards it is essential to identify and classify the risks in a more meaningful way. Hence, a preliminary hazard analysis (PHA) and risk assessment were carried out, and the results were discussed below.

Preliminary Hazard Analysis (PHA) is defined as a safety analysis tool used for identifying hazards, related causal factors and hazardous effects, risk level, and which provides mitigating design measures [27]. PHA evaluates the system design at the preliminary level without comprehensive information. The main aim of the PHA is to analyze the hazards that were identified in the Preliminary Hazard List (PHL) and to identify previously unrecognized hazards early in the system development. It identifies the hazard causal factors, consequences, and relative risk associated with the initial design concept. The PHA applies to the "analysis of all types of systems, facilities, operations, and functions and can be performed on a subsystem, system, or an integrated set of systems" [29]. A Preliminary Hazard Analysis (PHA) was conducted for the hazards related to pilot proficiency that was affected due to the pandemic, and the results of PHA were provided in Table 2.

Risk assessment provides a better appreciation regarding the prioritization of hazards and what type of preventive action or mitigation should be developed for each hazard identified. The two components measured under the risk classification or assessment are likelihood (probability for the event to happen) and severity (measure how considerable the damage will be if the event occurs). A failure to follow up after hazard identification is considered as a breakdown within the safety chain. This study intends to assess the identified hazard using system safety techniques, as it helps to take a holistic approach towards hazard mitigation. Based on the PHA, three 1C and one 1B hazard were identified related to pilot proficiency. These hazards were in the high-risk category due to the severity and probability of occurrence as categorized in the risk assessment matrix of the MIL-STD-882E document. If the preventive measures specified in this report were implemented, the risks can be reduced to a greater extent (Table 2).

Table 2 Preliminary Hazard Analysis of Pilot Proficiency due to COVID - 19

\begin{tabular}{|c|c|c|c|c|c|}
\hline Hazard & Cause & Effects & $\begin{array}{l}\text { Initial } \\
\text { Mishap } \\
\text { Risk } \\
\text { Index } \\
\text { (IMRI) }\end{array}$ & $\begin{array}{l}\text { Preventive actions/ } \\
\text { Mitigation }\end{array}$ & $\begin{array}{l}\text { Final } \\
\text { Mishap } \\
\text { Risk } \\
\text { Index } \\
\text { (FMRI) }\end{array}$ \\
\hline \multirow[t]{3}{*}{$\begin{array}{l}\text { Diminished } \\
\text { aircrew } \\
\text { proficiency/ } \\
\text { currency }\end{array}$} & $\begin{array}{l}\text { Significant } \\
\text { reduction of } \\
\text { flights due to } \\
\text { COVID-19 }\end{array}$ & $\begin{array}{l}\text { Controlled Flight } \\
\text { into Terrain (CFIT) } \\
\text { - Death or Injury }\end{array}$ & $1 \mathrm{C}$ & \multirow{3}{*}{$\begin{array}{l}\text { Conduct an extensive } \\
\text { and regular re- } \\
\text { currency or } \\
\text { proficiency flight to } \\
\text { ensure pilots are able } \\
\text { to maintain } \\
\text { proficiency. }\end{array}$} & $4 \mathrm{C}$ \\
\hline & $\begin{array}{l}\text { Limited access } \\
\text { to proficiency } \\
\text { tools } \\
\text { (Simulators/ } \\
\text { aircraft) due to } \\
\text { furlough and } \\
\text { lay-offs }\end{array}$ & $\begin{array}{l}\text { (CFIT) - Death or } \\
\text { Injury } \\
\text { Loss of aircraft } \\
\text { Control-Inflight } \\
\text { (OC-I) - Death or } \\
\text { Injury }\end{array}$ & $\begin{array}{l}1 \mathrm{C} \\
1 \mathrm{C}\end{array}$ & & $\begin{array}{l}4 \mathrm{C} \\
4 \mathrm{C}\end{array}$ \\
\hline & $\begin{array}{l}\text { Inability to } \\
\text { comply with } \\
\text { currency } \\
\text { requirements }\end{array}$ & $\begin{array}{l}\text { Un-stabilized } \\
\text { approach - Death or } \\
\text { Injury }\end{array}$ & $1 \mathrm{~B}$ & & $4 \mathrm{C}$ \\
\hline
\end{tabular}




\section{Recommendations and Conclusion}

Pilots must maintain currency and proficiency to operate an aircraft, and it is accomplished through recurrent training and observation flights piloted in simulators or an actual flight. Due to the global pandemic, air travel is affected significantly at both national and international levels, and so several airlines have furloughed and laid-off pilots and flight crewmembers. These lay-offs, furloughs, and lack of training/practice might lead to the expiration of pilots' currency. The Federal Aviation Administration has temporarily waived some requirements and has given extensions for pilot currency certifications. This waiver is for the pilots who are unable to comply with federal regulations due to the coronavirus. However, being legal to fly or complying with the minimum regulatory requirements, "currency" does not translate to being proficient. Due to the social distancing and related safety measures, other pilot certification requirements like the training facilities, inspectors, and examiners are also not available.

The present research determined that lack of practice will affect the pilot currency and proficiency during this pandemic. This might pose a risk and affect aviation safety when the demand for air service increases at a faster pace than the industry expects. As a result of this research study, several recommendations are made as an alternative means of compliance with conventional training and checking methods to mitigate the risk proactively.

- Aviation training centers are considered a non-essential activity and are closed during this pandemic. These aviation-training centers should start their training program through distance learning modalities. It can either switch to entirely online or a hybrid modality - a combination of online and videoconferencing using Zoom, Skype, Adobe Connect, or other tools.

- $\quad$ Flight simulation is proved to be a critical tool in ensuring pilot proficiency, especially within Part 121 or 135 operations. One setback that furloughed or laid off pilots have is the lack of access and the cost of FAA-approved level C or D simulator training. One approach is a public and private partnership to provide access and funding for the availability of these simulators or other flight training devices (FTD), especially to furloughed and laidoff pilots while waiting for the industry to pick up its pace.

- Airlines can offer virtual reality (VR) training for their pilots using Virtual 360 Editor cockpit training technology. This training requires just a computer, a virtual reality headset, and a pair of controllers, which is easily affordable. In VR training, pilots will have an opportunity to familiarize themselves in the virtual cockpit and practice the procedures. This virtual training can also be accomplished either in a solo environment or as a crew by adopting COVID-19 safety measures. This will help pilots effectively use the training time, maintain their skills, and help airlines in cost-savings. During this unprecedented time, FAA can provide certification for these programs.

- An industry approach to safety data gathering that is non-punitive should be developed. So that pilots can report the areas of concern then includes them in the training programs. An industry-oriented database system should be developed so that pilots can report the areas of concern that should be included in the training programs.

- Organizational SMS should be enhanced to include another safety net for hazard detection, classification, and mitigation relating to pilots who are potentially non-proficient despite being legally current to fly.

- Aviation testing activities also comes under non-essential activity. Due to the social distancing and related safety measures, line check airmen, safety inspectors, and pilot examiners are unavailable in some areas. FAA should take appropriate safety measures, including the use of personal protective equipment (PPE) or other measures to ensure that examinations or inspections should be done regularly.

- Another approach that the FAA can look into is establishing the Virtual Pilot Proficiency Center as an alternative measure to complete certain testing and certifications before the date of expiration. It can address the current line check backlog and ensure that airmen have met and exceeded minimum currency requirements to a degree of proficiency.

- Flight simulation has developed to a greater extent in a way that pilots can personally use the Microsoft Flight Simulator 2020 for training as the price is affordable. It offers a wide variety of aircraft models to choose from and offers over 37,000 airports that make it easy for the user to take-off and land in any airport around the world. The cockpit environment is detail-oriented, and extremely accurate with realistic weather effects. It is possible to fly in a range of light and visibility conditions across day and night. This simulation will help pilots to keep their mind-set active until they can start flying.

The recommendations from this study would require a lot of effort and funding. The financial side of aviation may look at safety as an expensive endeavour. When the pandemic finally ends and normalcy returns, safety audits and Line Operations Safety Assessments (LOSA) should be carried out. Monitoring routine operations will help to identify at-risk behaviours so that it can be proactively managed. Based on the hazard analysis it is recommended for the airlines to 
provide simulator training to pilots who are returning from furloughs and lay-offs. This will help to reduce the risks and enhance safety.

Several studies have concluded that it is expensive for an organization to react to an accident than prevention. Preventive measures reduce the probability of accident occurrences through mitigation. An excellent example is the Boeing 737 Max crash of Ethiopian Airlines flight 302 and Lion air flight 610 that lead to almost two years of grounding and litigations filed in various courts. So, safety professionals must continuously measure and evaluate several scenarios that pose a safety risk to the industry. The aviation industry is the backbone of every nation's social and economic development. Therefore, proactive measures must be taken to ensure the safety of the aviation industry.

\section{Compliance with ethical standards}

\section{Acknowledgments}

The authors would like to thank Professor Patricia Beck, Embry-Riddle Aeronautical University - Worldwide, PhoenixMesa Campus, Arizona, USA for the encouragement during the study. They also thank their families for their support during this unprecedented time to carry out this research.

\section{Disclosure of conflict of interest}

There are no conflicts of interest.

\section{References}

[1] Voltes-Dorta, Pagliari R. The impact of recession on airports' cost efficiency. Transport Policy. 2012; 24: 211222.

[2] Mehta P. Aviation During and Post Pandemic COVID-19 - Impact and Strategies. SF Journal of Aviation and Aeronautical Science. 2020; 2 (1): 1013.

[3] International Civil Aviation Organization [ICAO]. (2020a). Effects of Novel Coronavirus (Covid-19) on Civil Aviation: Economic Impact Analysis.

[4] International Air Transport Association [IATA]. (2020). COVID-19. Fourth Impact Assessment. International Air Transport Association.

[5] International Civil Aviation Organization [ICAO]. (2020b). COVID-19 Air Traffic Dashboard.

[6] Federal Aviation Authority. Pilot Proficiency Training. 2019.

[7] International Civil Aviation Organization [ICAO]. (2020c). Accident Statistics.

[8] Cohut M. Novel Coronavirus: Your questions, answered. 2020.

[9] Grennan D. (2019). What is a pandemic? The Journal of the American Medical Association. 2019; 321(9): 910910.

[10] World Health Organization (WHO). 2020. WHO Timeline - COVID-19.

[11] Dunford D, Dale B, Stylianou N. Lowther E, Ahmed M, Arenas IdlT. Coronavirus: The world in lockdown in maps and charts. 2020.

[12] Yale. How Pandemics End? 2020.

[13] Ammons RB, Farr RG, Bloch E, Neumann E, Dey M, Marion R, Ammons CH. Long-term retention of perceptualmotor skills. Journal of Experimental Psychology. 1958; 55(4): 318-328.

[14] Fleisman EA, Parker JF. Factors in the retention and relearning of perceptual-motor skill. Journal of Experimental Psychology. 1962; 64(3): 215-216.

[15] Childs JM, Spears WD, Prophet WW, Embry-Riddle Aeronautical University, Seville Research Corporation, \& Federal Aviation Administration Technical Center (U.S.). Private pilot flight skill retention 8, 16, and 24 months following certification. Springfield, Va; Atlantic City Airport, N.J; Federal Aviation Administration Technical Center. 1983. 
[16] National Transportation Safety Board. Aircraft Accident Report: Loss of Control on Approach, Colgan Air, Inc., Operating as Continental Connection Flight 3407, Bombardier DHC 8 400, N200WQ (NTSB Report No. AAR-1001). 2010.

[17] Johnson G. United Pilot Inexperienced in Landings Nearly Crashed 747. 1999.

[18] Puentes A. The Manual Flight Skill of Airline Pilots. 2011.

[19] Wright RH. Retention of flying skills and refresher training requirements: Effects of nonflying and proficiency flying. Fort Rucker, Ala: HumRRO Div. no. 6 (Aviation), Human Resources Research Organization. 1973.

[20] Arthur Jr W, Bennett Jr W, Stanush PL, McNelly TL. Factors that influence skill decay and retention: A quantitative review and analysis. Human Performance. 1998; 11(1): 57-101.

[21] Baron S. Pilot Control. In Weiner, E.L. \& Nagel, D.C. (Eds.), Human Factors in Aviation. San Diego, CA: Academic Press, Inc. 1988; 347-385.

[22] Bureau of Transportation Statistics [BTS]. U.S. Air Carrier Traffic Statistics. 2020.

[23] Creswell JW, Creswell JD. Research design: Qualitative, quantitative, and mixed methods approaches (5th Ed.). Thousand Oaks, CA: SAGE. 2018.

[24] Olaganathan R. Safety Analysis of Automatic Dependent Surveillance - Broadcast (ADS-B) System. International Journal of Aerospace and Mechanical Engineering. 2018; 5(2): 9 - 18.

[25] Department of Defence. Department of Defence Standard Practice - System Safety (MIL-STD-882E). 2012.

[26] Rausand M. Risk Assessment: Theory, Methods, and Applications. US: John Wiley \& Sons, Inc. 2011.

[27] Ericson CA. Hazard Analysis Techniques for System Safety. (2nd Ed.). New York, NY: Wiley Inter Science. 2015.

[28] Stolzer AJ, Goglia JJ. Safety Management Systems in Aviation (2nd Ed.). 2015.

[29] Ericson CA. Preliminary Hazard Analysis. In Hazard analysis techniques for system safety. New York: Wiley Inter science. 2005. 